\title{
EL VÍDEO TUTORIAL COMO GÉNERO DISCURSIVO EN LA PROYECCIÓN Y DESARROLLO DE LA COMPETENCIA ORAL EN SECUNDARIA
}

\author{
Recepción: 17/10/2018 | Revisión: 20/11/2018 | Aceptación: 09/08/2019 \\ Maria Pilar ROMÁN SANCHIS \\ Universitat de València \\ m.pilar.roman@uv.es \\ pilarroman@escolapiasgandia.org
}

\begin{abstract}
Resumen: Enseñar y evaluar la competencia oral puede resultar más sencillo en los nuevos escenarios de aprendizaje mediante herramientas TIC. Aquí se muestra una experiencia de aula cuyo objetivo es verificar que, con los nuevos géneros discursivos surgidos en la sociedad digital del aprendizaje, como el vídeo tutorial, se contribuye a dar sentido y contextualizar el desarrollo de la competencia oral, así como, que el docente es el que debe presentar escenarios de aprendizaje y planificarlos. El profesor debe descubrir y asumir qué competencias y rol debe desarrollar y, con este fin, enfocar su formación. Los nuevos escenarios digitalizados en el aula no deben estar exentos de metodología para poder concretar los objetivos de aprendizaje en la competencia oral.
\end{abstract}

Palabras clave: competencia oral; evaluación; rol docente; tutorial; TIC.

\section{TUTORIAL VIDEOS AS DISCURSIVE GENRE IN THE PROJECTION AND DEVELOPMENT OF ORAL COMPE- TENCE IN SECONDARY EDUCATION}

\begin{abstract}
Teaching and assessing oral competence can be easier in new learning scenarios using ICT tools. Here you can learn about a classroom experience whose objective is to verify that the new discursive genres emerged in the digital learning society, such as the video tutorial, help to make sense and to contextualize the development of oral competence. Also, it is stated that it is the teacher who must offer learning stages and plan them. Teachers need to find out which skills they should develop and which role they should take on so they can gear their training. The new digitalized scenarios in the classroom should not be exempt from methodology in order to achieve the learning targets in oral competence.
\end{abstract}

Keywords: oral skills; assessment; teaching role; tutorial; ICT (information and communication technologies).

\section{EL VÍDEOTUTORIAL COM A GĖNERE DISCURSIU EN LA PROJECCIÓ I DESENVOLUPAMENT DE LA COMPETĖNCIA ORAL A SECUNDÀRIA}

Resum: Ensenyar $i$ avaluar la competència oral pot resultar més senzill en els nous escenaris d’aprenentatge mitjançant eines TIC. Aquí es mostra una experiència d'aula l'objectiu de la qual és verificar que, amb els nous gèneres discursius sorgits en la societat digital de l'aprenentatge, com ho pot ser el vídeo tutorial, es contribueix a donar sentit i contextualitzar el desenvolupament de la competència oral, $i$ que el docent és el que ha de presentar escenaris d'aprenentatge i planificar-los. El professor ha de descobrir $i$ assumir quines competències $i$ rol ha de desenvolupar $i$, amb aquesta finalitat, enfocar la seva formació. Els nous escenaris digitalitzats a l'aula no han d'estar exempts de metodologia per a poder concretar els objectius d'aprenentatge en la competència oral.

Paraules clau: competència oral; avaluació; rol docent; tutorial; TIC. 


\section{Introducción}

En la mayoría de las ocasiones, la enseñanza y evaluación en la etapa de Secundaria se centra en los géneros discursivos escritos, obviando otras competencias como la oral. Resulta una paradoja la falta de tradición docente en la enseñanza oral y la ausencia de esta habilidad a pesar de estar presentes en las normativas de los diferentes currículums. Es además el propio sistema educativo (Martínez, 2002) el que hace referencia a la importancia de esta competencia e invita a construir discursos orales que se elaboren en contextos comunicativos adecuados, se escuche de manera activa interpretando las ideas del resto e incluso recreando escenarios que posibiliten la interacción del alumno. Todo esto, sin obviar habilidades que derivan del uso de la lectura, escritura y la aplicación de las TIC.

La normativa en el currículo ya señala la importancia de basarse en el aprendizaje por competencias, y para propiciarlo menciona la necesidad de una renovación en las tareas y planteamientos metodológicos (RD, 112, 2007). A esto, debemos añadir que la era digital atiende a nuevos comportamientos, acciones y oportunidades de aprendizaje que han aparecido a medida que las TIC han ido avanzando y se han vuelto de alguna manera omnipresentes.

Los motivos que impulsan el desarrollo de esta experiencia de aula parten de un enfoque metodológico basado en la investigación-acción. Fruto de esta investigación-acción parte la consideración del impacto de un contexto digitalizado, cómo de alguna manera se han tenido en cuenta estos avances, y se han instaurado en las prácticas del aula combinadas con otras prácticas tradicionales. El diseño de esta propuesta también parte de la observación de otros proyectos, en cuyo contexto digitalizado no se ha constatado el desarrollo de la competencia oral y su evaluación. En este contexto surge una propuesta didáctica que a su vez ha sido objeto de una investigación-acción donde se ha planificado, actuado y reflexionado.

El aula supone una prolongación de la sociedad digitalizada, esto también comporta cambios y nuevas perspectivas. Sales (2009) nos habla de la riqueza de las interacciones existentes entre ambas realidades, las consecuencias que de ello puedan derivarse en un contexto educativo concreto, y que es algo que ha sido estudiado escasamente desde una perspectiva investigadora. Esta nueva visión más amplia en la que se tiene en cuenta el surgir de nuevos géneros discursivos, como pueden ser los vídeo tutoriales, tendría presente que se puede aprovechar el conocimiento que tienen de estos los alumnos de secundaria, con la creación de estos se generarían instrumentos didácticos de enseñanza y aprendizaje, y conseguirían un refuerzo de las destrezas comunicativas orales junto con la combinación de instrumentos y aplicaciones digitalizadas.

\section{Estado de la cuestión}

Se ha considerado que los dos constructos de la producción textual humana son la oralidad y la escritura pero el tema de la oralidad rebasa los confines de la escritura y se requiere de la inserción de un nuevo constructo, la escrituralidad (Mostacero, 2004). Según Mostacero, hablaríamos de otra manera de comunicar la experiencia humana, la digitalización. Mostacero considera al 
hombre como un textualizador, un productor de textos y discursos. Así pues, teniendo en cuenta la hibridación natural que se da en el uso en los diversos contextos de interacción, Mostacero considera que se puede proponer una clasificación de los tipos textuales a partir de la premisa de que no existen textos orales y escritos puros, sino preponderantemente orales o escritos. Sobre esta base sugiere la existencia de los siguientes tipos: textos predominantes orales, escritos, mixtos, audiovisuales (estos combinan voz, escritura, imagen) computarizados y semióticos.

Alude a la teoría del contínuum como base teórica que permite interrelacionar las variedades tanto de la oralidad como de la escrituralidad (Mostacero, 2004). Esto permitiría comprender que lo oral se transforma en texto escrito y lo escrito se plasma en texto oral. El propósito que plantea es:

\begin{abstract}
Deslindar oralidad de escritura y construir el nicho epistémico para la escrituralidad. Demostrar que la oralidad se plasma en todas las manifestaciones de la semiosis y que las clases de oralidad no desaparecen en el entramado de la escrituralidad ni en las innovaciones de la comunicación electrónica. (Mostacero, 2004:73).
\end{abstract}

Por el contrario, considera que la oralidad se ha nutrido gracias a la tecnología (vídeos, audio cuentos, etc). De este modo, según dice Mostacero (2004):

\begin{abstract}
Esa es la razón por la que gracias a esta teoría es posible estudiar los casos de hibridación, de transferencias que caracterizan a las modalidades polifónicas del discurso donde las aplicaciones pueden ser textuales, pragmáticas, discursivas y didácticas. Esto permite dar cabida a todas o casi todas las manifestaciones de la producción textual humana desde las analógicas a las digitales. (Mostacero, 2004:73).
\end{abstract}

Por otro lado, los géneros discursivos sitúan el acto de escribir, hablar o conversar como actos de producción textual en situaciones concretas de comunicación social (Camps y Ribas, 2000, citado por Abad Beltrán: 106). Con el género discursivo asociamos un ámbito social, una función comunicativa, un formato y unas características lingüísticas. Por esto, es necesario contextualizar el aprendizaje en situaciones comunicativas, y concebir que aprender a usar un tipo de enunciado en una esfera de comunicación determinada es apropiarse de los géneros como instrumentos semióticos (Ribera, 2008, citado por Beltrán: 106).

Cassany dice que "el entorno digital facilita la creación de géneros nuevos que poco a poco están estandarizando usos lingüísticos" (Cassany, 2002:11). Además, "la falta de situaciones auténticas de comunicación en la escritura abre un abanico amplísimo de posibilidades para los alumnos" (Cassany, 2002: 16). Esto podría trasladarse igualmente a la comunicación oral.

Bakhtin (1982) acuñaba el concepto de género discursivo como un conjunto de enunciados orales o escritos que empleamos en determinadas situaciones y condiciones. Considera que el lenguaje se emplea de forma distinta dependiendo de la actividad o situación en la que nos encontremos. Por otro lado, el concepto de género discursivo se ha utilizado en la enseñanza de la lengua oral y escrita, y considera que permite al aprendiz apropiarse del lenguaje para utilizarlo en situaciones concretas:

Los géneros discursivos sitúan el acto de escribir, hablar o conversar como actos de producción textual en situaciones concretas de comunicación social. En este sentido, una de las grandes aportaciones del equipo de Bronckart de la Universidad de Ginebra es mostrar que el apren- 
dizaje de la composición escrita no es general: una persona no aprende a escribir cualquier texto sino que aprende a escribir un género concreto. Así, este aprendizaje se define como la apropiación de una gran diversidad de géneros discursivos, cada uno de ellos con sus funciones propias y sus rasgos lingüísticos específicos (Camps y Ribas, 2000:24, citado por Beltrán: 106).

Lo más destacado es que este concepto ha variado con el desarrollo de las tecnologías y numerosos recursos digitales. Según Cassany (2002), las características de los géneros discursivos son nuevas, y establece una diferencia entre textos planos, emergentes y autóctonos a los cuales caracteriza por formatos distintos y que no son equiparables a los géneros tradicionales. Con esto, el resultado sería una forma diferente de comunicarnos, crear contenidos y expresarnos como consecuencia de la evolución de herramientas tecnológicas.

En este sentido, los géneros han sido objeto de aprendizaje y es conveniente recrear la situación comunicativa en el aula y contextualizarlos en el ámbito de uso para que el alumno aprenda a utilizarlo. Previamente, la selección del género debe realizarse atendiendo a un objetivo didáctico, al mismo tiempo que se convierte en instrumento de evaluación (Vilà y Gómez, 2005).

Vilà (2011) manifiesta una defensa de la intervención didáctica que tiene como finalidad sostener que hablar bien no es una cualidad innata, ni es fruto de la creación de situaciones comunicativas que el profesor plantea en el aula. Existe una necesidad de negociar y gestionar la interacción social. Parte de la idea de que la competencia oral es necesaria para interactuar en nuestras aulas. Por consiguiente, no está de más que también se guie e intente alcanzar un nivel de oralidad adecuado que refleje el uso y consecución de una competencia oral en Secundaria.

El diálogo intencionado, según Vilà (2011), es una fuente de aprendizaje, es útil para la reflexión si se planifica el trabajo oral. Pero para mejorar esa competencia oral, considera que es necesario saber reconocer los registros adecuados en cada situación comunicativa y aconseja el uso de las secuencias didácticas que pueden acercar fácilmente esas situaciones en un contexto significativo. Destaca que en la planificación de estas secuencias está la base de la incorporación de estrategias comunicativas, y que estas pueden ser al mismo tiempo evaluadas. Esto implica que, en el proceso, los alumnos puedan reflexionar e interiorizar reglas discursivas. Todavía más si los alumnos son conscientes de que van a ser escuchados entre iguales.

Siguiendo esta línea, Martínez (2002) ya manifiesta la necesidad de abordar didácticamente la expresión oral y cómo esta debe ser fruto de un trabajo educativo. La aparición de las nuevas tecnologías han generado y favorecido una pedagogía de la expresión oral, pero para que puedan cumplir la función didáctica de la competencia oral no se deben olvidar las condiciones que Martínez (2002) nos plantea, y son los medios y recursos suficientes para crear espacios comunicativos.

Núñez (2003) ha insistido en la importancia de las destrezas orales y en la necesidad de estar preparados para poder asumir los cambios de la sociedad digital. La tecnología de transmisión de la información plantea nuevos patrones de interacción y la escuela no ha tenido en cuenta estas funciones, ni tampoco los objetivos para que la competencia oral esté presente en la educación. Además, alude que son razones instrumentales, psicológicas, sociales 
y culturales las que justifican que en la vida actual se exija un nivel de comunicación oral tan alto como el escrito.

No podemos olvidar que las sociedades con cultura escrita han surgido de tradición oral. Las diferencias entre la lengua escrita y oral (Núñez, 2003) están señaladas por fenómenos físicos y psicológicos distintos; debemos resaltar que la lengua oral es al mismo tiempo una producción rica. Núñez (2003) incide en la existencia de puntos en común y que será más sencillo lograr una competencia si se destacan las exigencias propias de cada una de ellas, y además se puedan complementar y relacionar. Atribuye la causa de la dejadez en el desarrollo de la competencia oral en las escuelas, precisamente, a la priorización de las diferencias en vez de las semejanzas. Desde la didáctica de lo oral, se requiere un análisis de la asociación generalizada entre lengua oral e informalidad y lengua escrita como formal (Núñez, 2003).

Si partimos de este marco, un género discursivo como el video tutorial (entendido como manual de uso en formato tecnológico) podría potenciar las situaciones de interacción oral en el aula y desarrollar la competencia oral mediante el diseño de tareas enmarcadas en una secuencia didáctica y, en el marco del aprendizaje basado en proyectos donde se pueden desarrollar estrategias claves para fomentar habilidades, conocimientos y actitudes.

\section{Descripción del procedimiento}

La competencia oral no es objeto de evaluación en la mayoría de las ocasiones, ni tan siquiera en las pruebas externas como PISA, PAU, o pruebas diagnósticas. En estas pruebas se evalúa la comprensión lectora y para poder evaluarla se utilizan textos escritos (Navarro Gutiérrez, 2013). La propuesta didáctica presentada contribuye al desarrollo de la competencia oral de los alumnos y su evaluación, crea contextos de aprendizaje y estrategias que pueden ayudar a completar la competencia comunicativa de los alumnos de secundaria, y tiene en cuenta la influencia del entorno digital en el que se ven inmersos muchos de nuestros alumnos. Todo esto es fruto de un nuevo modelo de sociedad digitalizada.

Al mismo tiempo, se tienen en cuenta los principios metodológicos claves para favorecer una enseñanza que ayude a la educación en la era digital. En esta, según Pérez Gómez (2012), prima la actividad aprendizaje como proceso activo de indagación. El foco de investigación acción se centra en resolver:

a) Si se puede desarrollar y evaluar la competencia oral de secundaria en los nuevos contextos digitalizados.

b) Si podemos aprovechar el conocimiento de estos nuevos géneros discursivos.

c) Si se puede convertir el vídeo tutorial en un instrumento didáctico.

d) Si el docente es parte activa en la contextualización en un entorno digital.

Partimos de las siguientes hipótesis: la validez del vídeo tutorial como género discursivo e instrumento didáctico como instrumento para motivar el aprendizaje, ayudar a contextualizar y desarrollar la competencia oral; el papel fundamental y la importancia de la intervención pedagógica en la enseñanza oral en entornos digitales, y el descubrimiento del rol del docente en entornos digitales. 
Los objetivos que se marcan son los siguientes: mostrar de qué modo los nuevos medios digitalizados son una oportunidad para desarrollar y evaluar la competencia oral; verificar que el vídeo tutorial es un nuevo género discursivo que reúne y contribuye a reconocer las características propias de los géneros textuales instructivos; entender la finalidad del vídeo tutorial como instrumento didáctico y de desarrollo de la competencia oral en la escuela, y contribuir en el descubrimiento de la función docente en los nuevos escenarios donde el uso de las herramientas TIC está presente.

\subsection{Metodología}

La experiencia de aula basada en un investigación-acción se ubica en el centro Escolapias de Gandía en Valencia durante el curso 2017-18, y se presenta en el marco de un aprendizaje basado en proyectos. La finalidad es el desarrollo de la competencia oral de alumnos de $3^{\circ}$ de ESO aprovechando los recursos tecnológicos que disponen, enmarcada en una secuencia didáctica en el proyecto Tutoriales de ortografía. El grupo lo forman un total unos 60 alumnos de la asignatura de Valenciano que es de Libre configuración.

En el centro se imparte docencia desde la etapa de Infantil a la de Bachillerato, lo que supone una oportunidad para diseñar la propuesta didáctica en dos contextos diferenciados: las aulas de Secundaria y las de Primaria. Se centra en un contexto digitalizado donde cada alumno dispone de un dispositivo electrónico. Es un colegio que lleva trabajando en su Plan Estratégico desde 2014 en la implantación de los avances de las TIC. De este modo, desde 2015-16 se implantó el Proyecto iEEG en Secundaria. Se trata de un cambio metodológico basado principalmente en el aprendizaje por descubrimiento y trabajo por proyectos colaborativos, todo ello a través de tabletas como vehículo de conexión y contenedor de recursos educativos y como herramienta TIC.

Para el objetivo en cuestión, se diseña una secuencia didáctica que se concreta en el marco de una metodología ABP (Aprendizaje Basado en Proyectos). Martín y Martínez (2018) la definen como el aprendizaje basado en la actividad, desarrollando actividades que requieren investigación, toma de decisiones y comunicación escrita. Se puede partir de un problema cuya finalidad es adquirir nuevos conocimientos e integrarlos. Esta información se adquiere a través de un aprendizaje autodirigido, y la enseñanza se centra en el estudiante, aprendiendo en grupos. El rol de los profesores se sitúa en el de facilitadores o guías en lugar de como transmisores de información. Kolmos (2004) explica que este modelo se entiende como una manera de organizar los procesos de aprendizaje, lo que crea un modelo pedagógico particular y el trabajo final es fruto de la elaboración grupal. En definitiva, considera que el ABP es una unidad didáctica integrada.

La secuencia didáctica diseñada se centra en la planificación de un discurso oral cuya finalidad es la grabación de un vídeo tutorial, la exposición oral de estos entre iguales y la escucha activa de los vídeo tutoriales sobre las normas ortográficas de la lengua objeto de estudio: el valenciano. Todo esto en diferentes contextos entre alumnos de Secundaria y alumnos de Primaria.

El vídeo tutorial entendido como un manual de soporte electrónico recoge las características lingüísticas propias de los textos instructivos, y como tal se planifican las sesiones, es decir, que 
los alumnos consigan además con esta secuencia didáctica usar los procedimientos lingüísticos que entran en juego en relación con el género discursivo que se trabaja.

La naturaleza oral del vídeo tutorial fomentará la expresión oral en la lengua objeto de estudio, al mismo tiempo que el formato digital supondrá una motivación añadida a las dificultades de expresión oral que muchos alumnos presentan en la lengua cooficial.

Por otro lado, se planifican dos exposiciones orales bien diferenciadas:

- La que realizan los alumnos de $3^{\circ}$ de ESO en su propia clase de $3^{\circ}$.

- La que los alumnos de $3^{\circ}$ de ESO exponen a los alumnos de primaria.

La tarea final consiste en mostrar los vídeo tutoriales y su escucha activa junto con una exposición oral de actividades diseñadas para determinar el desarrollo de la competencia oral y el grado de adquisición y/o aprendizaje sobre las normas expuestas.

\subsection{Fases de la SD y planificación}

Las fases de la secuencia didáctica están divididas a su vez en varias sesiones donde se inicia una actividad dirigida a evaluar y valorar el proceso.

En primer lugar, se realizó una presentación de una lectura inicial donde se recogieron las peculiaridades de las instrucciones y se buscó información sobre la definición de tutorial. La finalidad era que el alumno conociera qué es una instrucción, la multitud de formatos que puede presentar un tutorial y el valor didáctico que pueda tener el uso en formato digital.

En posteriores sesiones, se mostró un ejemplo de texto con las características propias de un tutorial escrito; el ejemplo que se tomó fue un Catálogo de la xarxa de lectura pública valenciana y sus partes; la finalidad era valorar la identificación de las características propias del tutorial en el texto escrito para aplicarlo posteriormente a un discurso oral y adecuarlo al contexto oral formal (Tablas de la 1 a la 3 ).

En la quinta fase se organizó la actividad para recoger información sobre la norma ortográfica de la cual se iba a realizar el tutorial, y consistió en la elaboración de un borrador y selección de información. En estas sesiones, la evaluación estaba centrada en la planificación, selección de información destacada de la norma, conocimiento de la normativa, sus aplicaciones, y el diseño de actividades para la exposición oral más acorde a la norma escogida y a la etapa a la cual iba a ir dirigida la exposición.

En la sexta fase se realizó la grabación de los vídeo tutoriales. La actividad consistía en recogida de materiales, borradores y ensayo de las lecturas de los mismos. Aquí, se observó la interacción que se llevó a cabo entre iguales. Además, la grabación requería la realización de un discurso oral, claro y conciso. Al mismo tiempo, durante la grabación, se precisaba de una selección previa de lo que se iba a decir, junto con una mayor atención en la pronunciación y entonación. Para algunos alumnos castellano parlantes esto suponía cierta dificultad. A esto, se sumaba la escucha activa del propio alumno, que fomentaba la autorregulación, ya que eran conscientes de que iban a ser escuchados por otros alumnos. Es decir, una audiencia que requiere de un discurso adecuado con cierto dominio de la expresión oral. Varias de las grabaciones muestran errores du- 
rante el proceso que se convierten en modelos de referencia para el alumno.

En la séptima fase se realizaron las exposiciones orales y actividades diseñadas por los alumnos de $3^{\circ}$ de ESO; la actividad se centraba en la escucha activa de los tutoriales de cada pareja, explicación de las actividades diseñadas y la posterior realización de las mismas; entre las actividades se realizaron Kahoot, fichas y ejercicios interactivos. En estas últimas sesiones, los alumnos realizaron una coevaluación mediante una rúbrica y el profesor pudo comprobar los resultados en las hojas de Excel de los Kahoot.

En la octava fase, también de varias sesiones, se concertaron las exposiciones de cada grupo de $3^{\circ}$ de ESO con el que tenía asignado de Primaria. Los vídeo tutoriales presentados se compartieron antes con las clases de primaria.

El día concertado se presentaron las exposiciones de los alumnos de $3^{\circ}$ de ESO en el aula de Primaria correspondiente y se realizaron las actividades de exposición. Durante esta, los alumnos entraban en un contexto y audiencia nuevos (en este caso en las aulas de los alumnos de primaria). En las clases Primaria, los alumnos de ESO mostraban con una presentación su vídeo tutorial y posteriormente explicaban tanto el proceso de creación del vídeo tutorial como el contenido del mismo, que trataba sobre la norma ortográfica que habían trabajado.

Aquí el profesor evaluó a los alumnos de $3^{\circ}$ de ESO mediante una lista de cotejo, en la cual se tenía en cuenta si se respetaba la estructura del discurso oral en los alumnos que se expresaban.

En la novena fase y última, se compartieron los vídeo tutoriales que previamente se habían colgado en un mural virtual. Finalmente, este mural se compartió con alumnos de $3^{\circ}$ de ESO y de Primaria para que se pudieran usar como material didáctico de instrucción sobre las normas de ortografía.

\begin{tabular}{|c|c|c|c|}
\hline Sesión & Actividad & Descripción & Qué evaluar y valorar \\
\hline \multirow[t]{2}{*}{$\begin{array}{l}1 \mathrm{a} \\
2^{\mathrm{a}}\end{array}$} & Lectura inicial de un texto donde se dan instrucciones & $\begin{array}{l}\text { Conocer la función del } \\
\text { tutorial. }\end{array}$ & \multirow{2}{*}{$\begin{array}{l}\text { Conoce qué es una } \\
\text { instrucción y reconoce el } \\
\text { valor didáctico que puede } \\
\text { tener el uso en formato } \\
\text { digital del tutorial }\end{array}$} \\
\hline & $\begin{array}{l}\text { Leer la definición del tutorial= Manual de uso en soporte } \\
\text { electrónico. }\end{array}$ & $\begin{array}{l}\text { Búsqueda de la } \\
\text { definición en la RAE, ver } \\
\text { la multitud de formatos } \\
\text { que presentan: } \\
\text { documento de texto, } \\
\text { presentación } \\
\text { PowerPoint, vídeo. }\end{array}$ & \\
\hline \multirow[t]{2}{*}{$\begin{array}{l}3^{\mathrm{a}} \\
4^{\mathrm{a}}\end{array}$} & Mostrar la estructura del tutorial & \begin{tabular}{|l} 
Leer y ver ejemplo \\
escrito de la consulta \\
del Catálogo de la xarxa \\
de lectura pública \\
valenciana y sus partes
\end{tabular} & \multirow{2}{*}{$\begin{array}{l}\text { Identifica el tutorial en el } \\
\text { texto escrito, su estructura y } \\
\text { características para aplicarlo } \\
\text { posteriormente a un } \\
\text { discurso oral. } \\
\text { Adecuar al contexto oral } \\
\text { forma. }\end{array}$} \\
\hline & $\begin{array}{l}\text { Identificar y relacionar las características del tutorial con las } \\
\text { propias de los textos instructivos }\end{array}$ & $\begin{array}{l}\text { Se identifican en el texto } \\
\text { las características: uso } \\
\text { de la primera persona } \\
\text { del plural, abundancia } \\
\text { de imperativos y de } \\
\text { perífrasis de obligación, } \\
\text { conectores de orden } \\
\text { que guían el proceso y } \\
\text { precisión léxica de un } \\
\text { vocabulario } \\
\text { especializado }\end{array}$ & \\
\hline
\end{tabular}

Tabla 1. De la $1^{\mathrm{a}}$ a la $4^{\mathrm{a}}$ fase de la secuencia didáctica. Fuente: Propia. 


\begin{tabular}{|c|c|c|c|}
\hline $\begin{array}{l}5^{\mathrm{a}}(3 \text { sesiones } \\
\text { de } 45 \mathrm{~m})\end{array}$ & $\begin{array}{l}\text { Organización sobre las normas ortográficas de las que van a } \\
\text { realizar el tutorial. }\end{array}$ & $\begin{array}{|lr|}\text { Búsqueda } & \text { de } \\
\text { información sobre las } \\
\text { normas. Elaboración de } \\
\text { un borrador, sintetizar y } \\
\text { seleccionar } & \text { la } \\
\text { información } & \\
\end{array}$ & $\begin{array}{l}\text { Planificación, identificación y } \\
\text { búsqueda de las normas } \\
\text { seleccionadas, saber } \\
\text { sintetizar las características } \\
\text { más destacadas. } \\
\text { Conocimiento de la } \\
\text { normativa sus aplicaciones. } \\
\text { Diseñar la actividad más } \\
\text { adecuada a la norma } \\
\text { escogida. Completar, } \\
\text { identificar, } \\
\end{array}$ \\
\hline \begin{tabular}{|l}
$6 \mathrm{a}$ \\
$(3$ sesiones de \\
$45 \mathrm{~m})$
\end{tabular} & Grabación del tutorial & $\begin{array}{l}\text { Materiales, borradores, } \\
\text { ensayos y lectura de los } \\
\text { borradores. }\end{array}$ & $\begin{array}{l}\text { Oralización del texto y } \\
\text { espacio de interacción, entre } \\
\text { iguales, aplican no solo las } \\
\text { destrezas que ya poseen, } \\
\text { deben grabar un discurso } \\
\text { claro, conciso, con la } \\
\text { selección previa de lo que se } \\
\text { va a decir, pronunciación, } \\
\text { entonación.. activa, se } \\
\text { Escucha se } \\
\text { autorregulan, son conscientes } \\
\text { que van a ser escuchados por } \\
\text { otros alumnos, una audiencia } \\
\text { que requiere de un discurso } \\
\text { adecuado con cierto dominio } \\
\text { de expresión oral. } \\
\text { Varias grabaciones muestran } \\
\text { errores que se convierten en } \\
\text { modelos de referencia. }\end{array}$ \\
\hline
\end{tabular}

Tabla 2. Fases $5^{\mathrm{a}}$ y $6^{\mathrm{a}}$ de la secuencia didáctica. Fuente: propia.

\begin{tabular}{|c|c|c|c|}
\hline $\begin{array}{l}7^{\mathrm{a}} \\
(3 \mathrm{sesiones} \text { de } \\
45 \mathrm{~m})\end{array}$ & $\begin{array}{l}\text { Escucha de los tutoriales, exposición oral y ejecución de la } \\
\text { actividad diseñada entre alumnos de } 3 \text { o }\end{array}$ & \begin{tabular}{|lrr} 
Escucha activa del & tutorial, explicación e \\
instrucción de de las \\
actividades & diseñadas, \\
posterior & realización de \\
las & actividades \\
diseñadas: & kahoot, \\
fichas, & ejercicios \\
interactivos.... &
\end{tabular} & $\begin{array}{l}\text { Coevaluación mediante } \\
\text { rúbricas. } \\
\text { Recogida de resultados del } \\
\text { kahoot que comparten con } \\
\text { los alumnos y profesor. }\end{array}$ \\
\hline $\begin{array}{lr}8^{\text {a }} & \\
\text { (Durante } & \text { el } \\
\text { trimestre, } & 2 \\
\text { sesiones } & \\
\text { semanales) } & \end{array}$ & $\begin{array}{l}\text { Exposición oral al grupo de alumnos de primaria } \\
\text { correspondiente: } \\
3^{\circ} \text { ESO A a } 5^{\circ} \text { de primaria } \\
3^{\circ} \text { ESO B a } 6^{\circ} \text { de primaria }\end{array}$ & $\begin{array}{l}\text { Se comparte el tutorial } \\
\text { unos días antes en las } \\
\text { clases de primaria. El día } \\
\text { concertado se presentan } \\
\text { y se exponen en el aula } \\
\text { de primaria } \\
\text { correspondiente y se } \\
\text { realizan las actividades y } \\
\text { ejercicios diseñados. }\end{array}$ & $\begin{array}{l}\text { Heteroevaluación. Saber } \\
\text { estructurar un discurso oral: } \\
\text { introducción, desarrollo y } \\
\text { conclusión. } \\
\text { Usar estrategias implicadas } \\
\text { en las instrucciones de uso. } \\
\text { Coevaluación }\end{array}$ \\
\hline $\begin{array}{l}9^{\text {a }}(3 \text { sesiones } \\
\text { semanales })\end{array}$ & $\begin{array}{l}\text { Visualización y escucha de los tutoriales en un mural virtual } \\
\text { compartido en Classroom. }\end{array}$ & $\begin{array}{l}\text { Se comparten todos los } \\
\text { tutoriales con los } \\
\text { alumnos de } 3^{\circ} \text { ESO A y B, } \\
\text { además de los alumnos } \\
\text { de } 55^{\circ} \text { y } 6 \text { de primaria en } \\
\text { un mural virtual Padlet } \\
\text { para que se puedan usar } \\
\text { como material didáctico } \\
\text { de instrucción sobre las } \\
\text { normas de ortografía. } \\
\text { Mural virtual tutoriales }\end{array}$ & $\begin{array}{l}\text { Contextualización. Dan un } \\
\text { sentido a las tareas } \\
\text { realizadas, } \\
\text { Se evalúa la utilidad del } \\
\text { tutorial como material } \\
\text { didáctico mediante una } \\
\text { rúbrica. }\end{array}$ \\
\hline
\end{tabular}

Tabla 3. De la $7^{\mathrm{a}}$ a la $9^{\mathrm{a}}$ fase de la secuencia didáctica. Fuente: propia.

\section{Interpretación de los resultados y observaciones de los alumnos}

La secuencia didáctica estaba dirigida a dos grupos de alumnos de $3^{\circ} \mathrm{ESO}$, un total de 60 alumnos. La recogida de información se hacía en base a lo que ellos percibieron y qué logros consiguieron. Se diseñaron cuestionarios dirigidos a los alumnos; la finalidad era obtener los datos sobre las observaciones de los alumnos durante el proceso de las grabaciones y las exposiciones orales presentadas por los propios alumnos de Secundaria, y de la escucha activa realizada por los alumnos de Primaria. 
Tal y como se ha mencionado, la lengua objeto de las tareas fue el valenciano. Una mayoría tenían el castellano como lengua materna, y no supuso un obstáculo añadido, ya que un $62 \%$ determinó que no tuvieron dificultad.

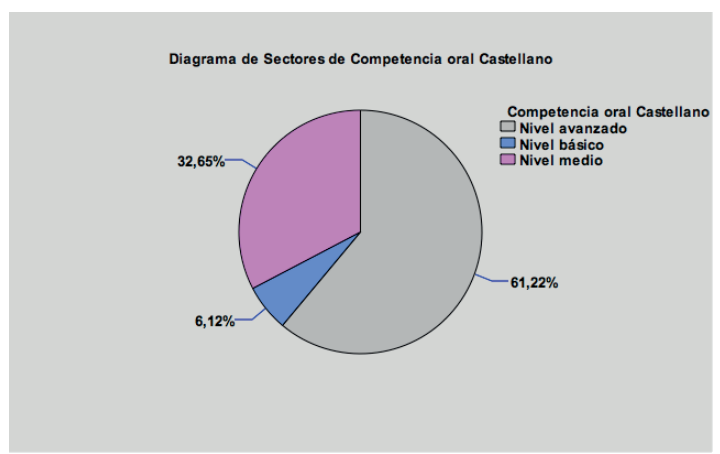

Figura 1. Competencia oral en castellano

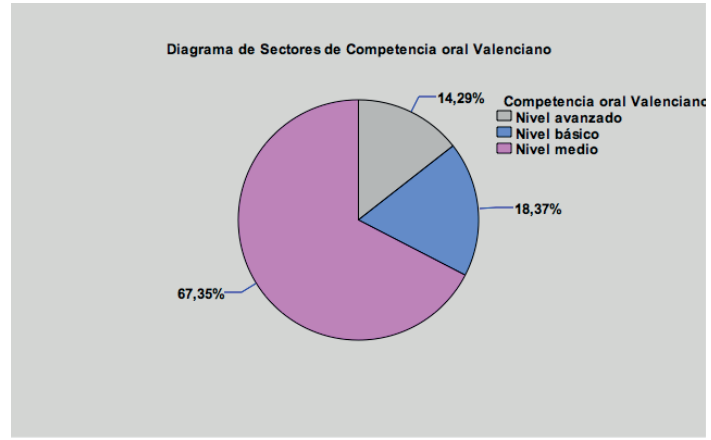

Figura 2. Competencia oral en valenciano

La competencia oral en valenciano era inferior a la de castellano. Sin embargo, coinciden los que dicen expresarse mejor en esa lengua con el nivel avanzado (Figuras 1 y 2). Los que se expresan mejor en castellano se consideran entre un nivel avanzado y medio. En las asignaturas del currículum en las cuales los alumnos consideran que se trabaja la expresión oral y además es evaluada (inglés, castellano y valenciano), son equiparables los porcentajes de la opción siempre (Figuras 3, 4 y 5). Los alumnos tienen la percepción que realizan tareas de expresión oral a veces. Esto se debería al hecho de que, a pesar de realizar actividades orales, no son evaluadas y están descontextualizadas; por consiguiente, las tareas de expresión oral no quedan definidas como tal.
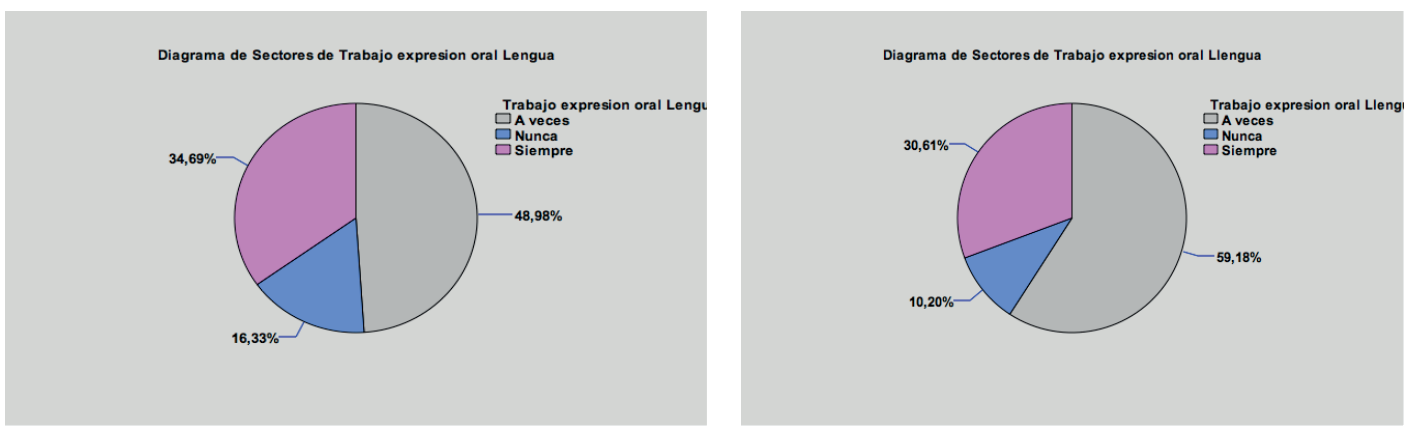

Figuras 3 y 4. Porcentajes de trabajo dedicado a la expresión oral en Lengua castellana y Valenciano.

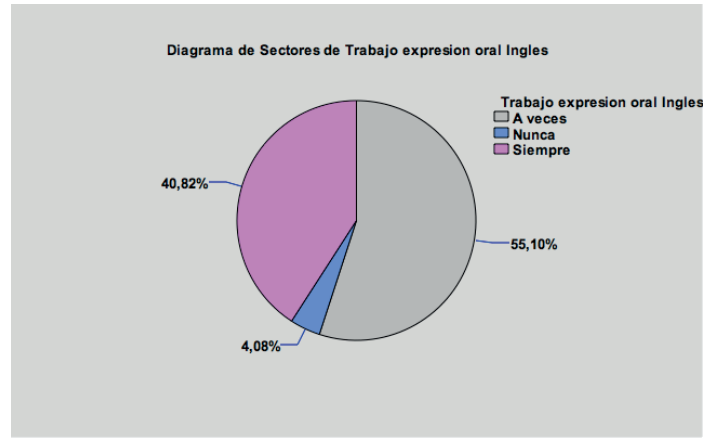

Figura 5. Porcentajes de trabajo dedicado a la expresión oral en inglés. 
En relación a las asignaturas de ciencias como Biología, Matemáticas, Tecnología y Física y Química (Figuras de 6 a 9), en todas predomina la opción nunca. Además, el margen de elección de la opción a veces se asemeja a las de lenguas. Es una muestra más de que la actividad oral en el aula es una constante, pero no queda registrado como un trabajo expreso ni definido. Es evidente, que no perciben las tareas de expresión oral como algo trabajado con continuidad. Una de las razones que justificaría esta percepción es el hecho de que no sea evaluada.
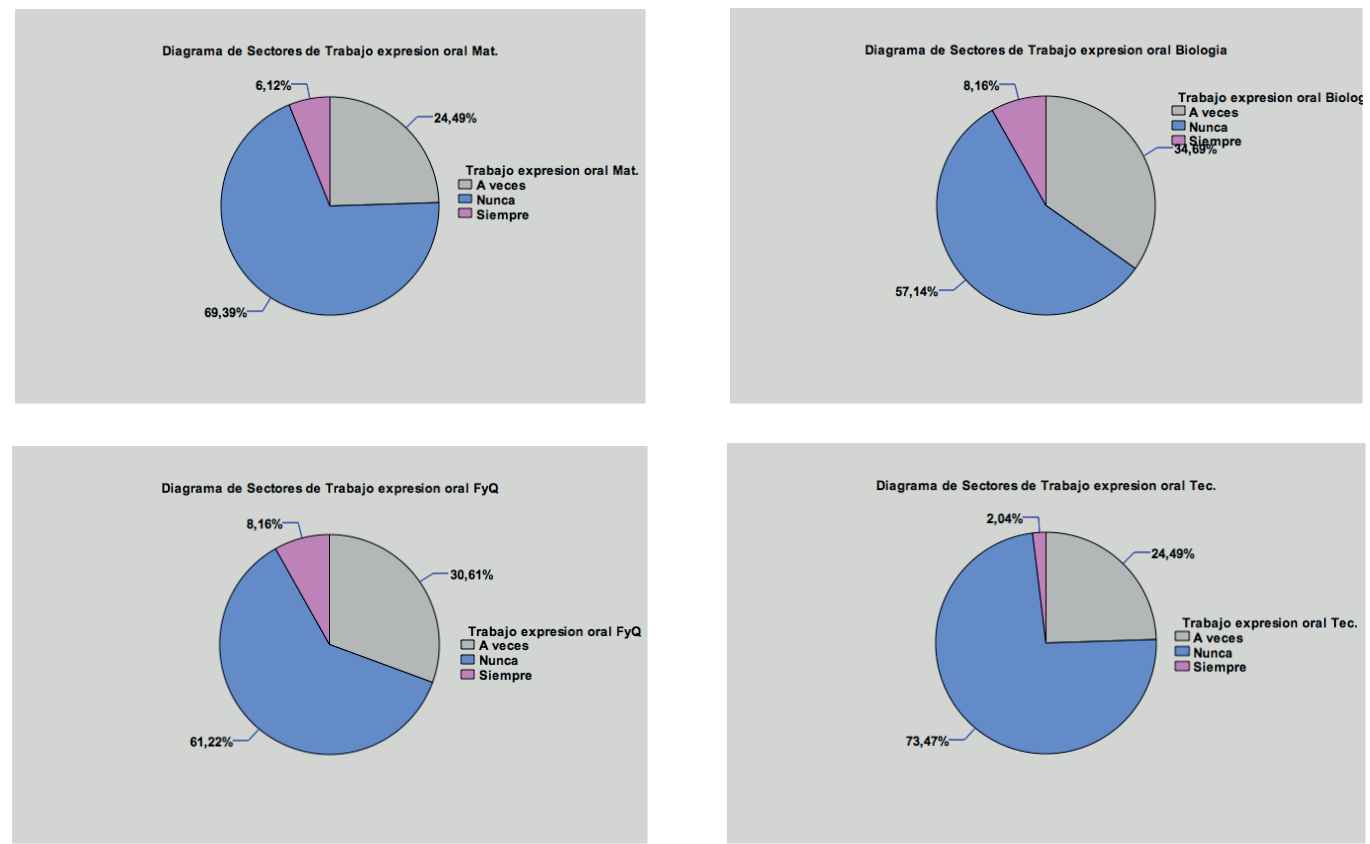

Figuras $6,7,8$ y 9. Porcentajes de trabajo dedicado a la expresión oral en Matemáticas, Bilogía, Física y Química y Tecnología.

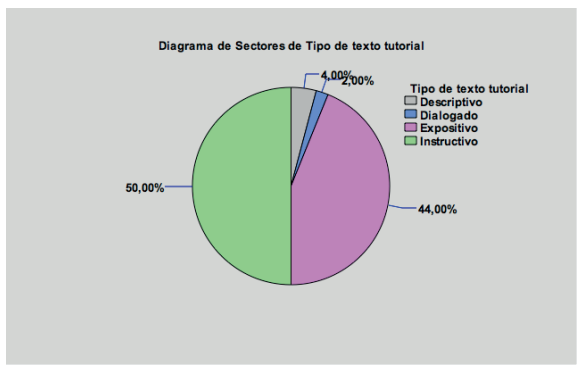

Figura 10 . Reconoce el vídeo tutorial a qué tipología textual pertenece.

La mitad de los alumnos al finalizar la secuencia reconoce en el vídeo tutorial las características propias de los textos instructivos, aunque aún se perciben una muestra de porcentajes que determinan otros tipos textuales (Figura 10). No podemos olvidar que los textos no son puros y que en un instructivo podemos encontrar secuencias textuales descriptivas o expositivas. Por lo tanto, los alumnos no se alejan de la finalidad del mismo. Es una prueba más de que el formato digital del género discursivo, el vídeo tutorial, no impidió reconocer la tipología textual propia. 


\subsubsection{Durante el proceso de construcción del vídeo tutorial y exposiciones orales en los alumnos de $3^{\circ}$ ESO}

En la Tabla 4 se muestran las observaciones y reflexiones en el proceso de tareas de la secuencia didáctica.

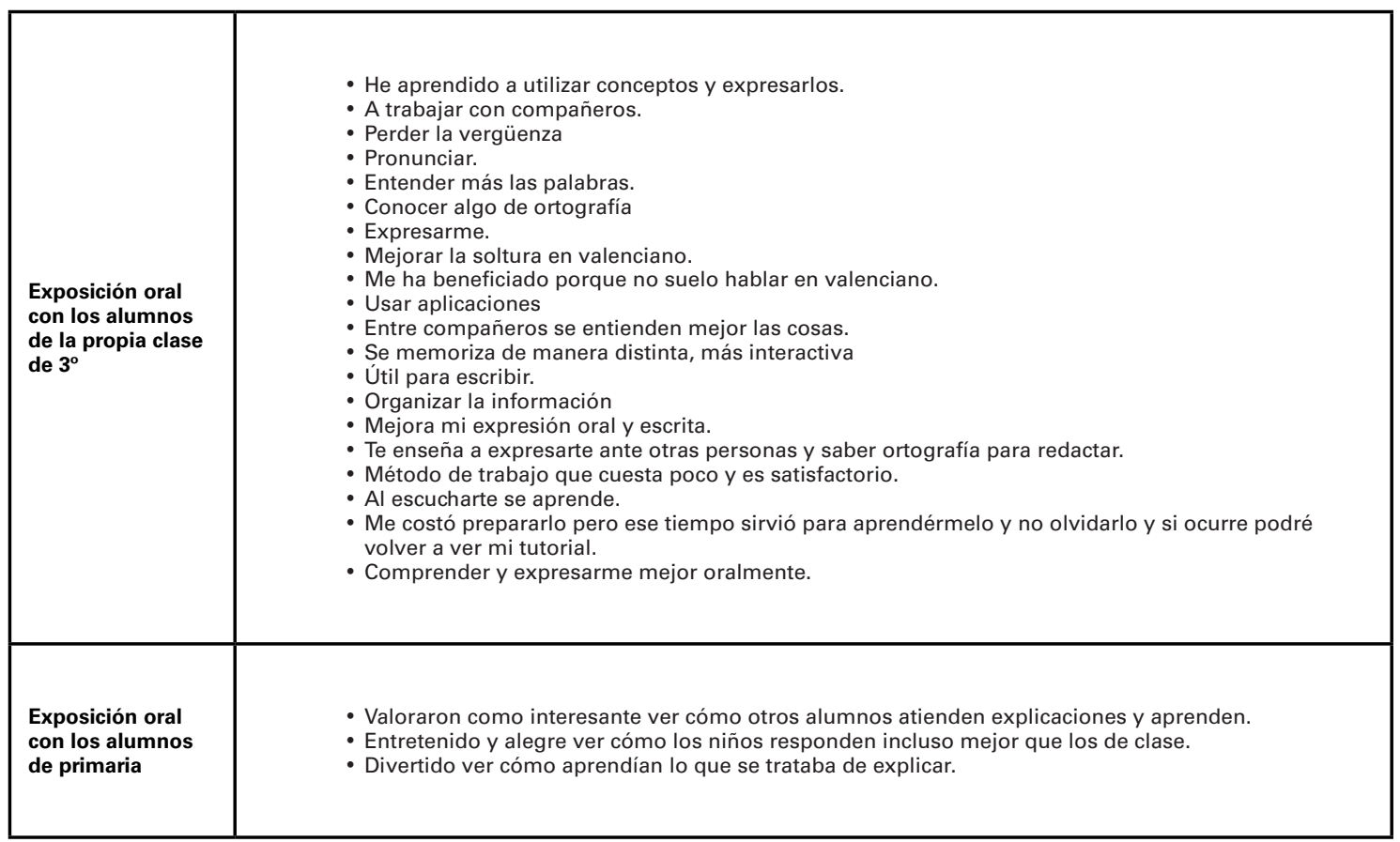

Tabla 4. Observaciones de los alumnos de $3^{\circ}$ de ESO en el proceso de exposición oral entre iguales con los alumnos de Primaria.

A estas cuestiones se sumaron si creían que las tareas de grabación del vídeo tutorial les habían ayudado a mejorar su competencia (Figura 11). A su vez, también se les preguntó si las TIC les habían ayudado a desarrollar su competencia oral (Figura 12). Un alto porcentaje consideró que sí, lo que demostraría la validez del vídeo tutorial para motivar el aprendizaje, y que las tareas de grabación han dado sentido y colaborado en el desarrollo de la competencia oral.

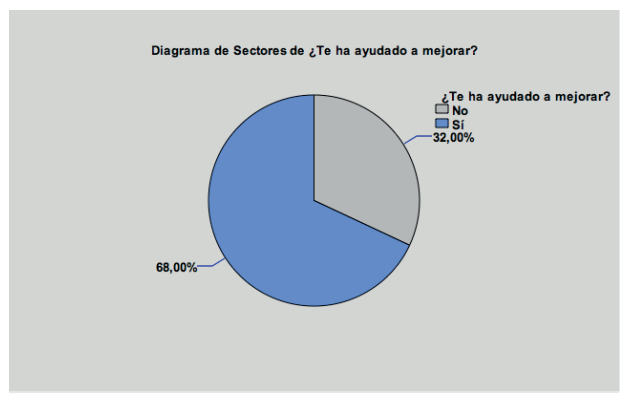

Figura 11. Si les ha ayudado a mejorar su competencia.

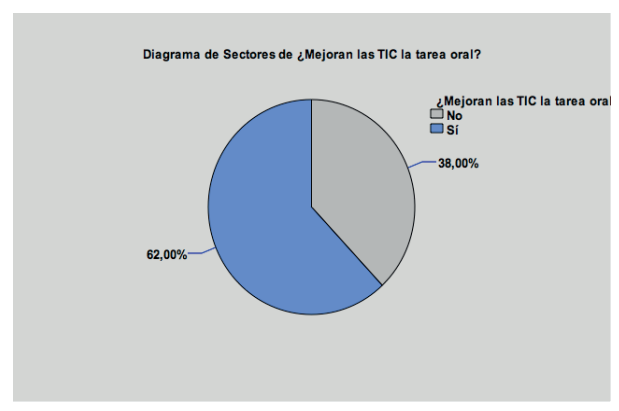

Figura 12 Mejoran las TIC la competencia oral. 


\subsubsection{Observaciones de los alumnos de Secundaria}

En la Tabla 4 (véase apartado anterior) se recogen las creencias de los alumnos de $3^{\circ}$ de ESO en dos contextos: en la exposición oral que hicieron entre iguales, y en la exposición oral que hicieron en otro contexto, ante los alumnos de Primaria. En ellas podemos ver las dificultades y beneficios que han considerado. Son numerosas las consideraciones relacionadas con la expresión oral entre iguales, y cómo hubo más escucha activa entre los alumnos de Primaria.

En la Tabla 5 se describen las justificaciones que los alumnos de $3^{\circ}$ de ESO consideraron fruto de una reflexión tras la escucha de las muestras de los video tutoriales. Estas muestran de forma clara cómo supone una oportunidad para la autorregulación de los alumnos, incluso, cuando deben tomar decisiones durante su intervención oral.

\begin{tabular}{|c|c|c|}
\hline Dificultades & $\begin{array}{l}\text { - Vocalizar } \\
\text { - Ser incapaz de expresarme. } \\
\text { - No saber pronunciar una palabra } \\
\text { - Conseguir que sea entendible al grabar } \\
\text { los audios. } \\
\text { - Intentar hacerlo más formal. } \\
\text { - Expresarnos formalmente. } \\
\text { - Pensar mejor si lo que decíamos } \\
\text { estaba bien o mal dicho } \\
\text { - Palabras que no sabía cómo traducirlas }\end{array}$ & \\
\hline Beneficios & $\begin{array}{l}\text { - He aprendido a utilizar conceptos y } \\
\text { expresarlos. } \\
\text { - A trabajar con compañeros. } \\
\text { - Perder la vergüenza, pronunciar. } \\
\text { - Entiendo más palabras que antes. } \\
\text { - Conocer algo de ortografía. } \\
\text { - Expresarme. } \\
\text { - Mejorar la soltura del valenciano. } \\
\text { - No suelo hablar en valenciano me } \\
\text { beneficia. } \\
\text { - Usar aplicaciones, fluidez en el habla } \\
\text { - Cosas nueva. } \\
\text { - Valenciano }\end{array}$ & $\begin{array}{l}\text { - Entre compañeros se entienden mejor } \\
\text { las cosas. } \\
\text { - Memorizar las normas de manera } \\
\text { distinta. } \\
\text { - Más interactiva, hago menos faltas de } \\
\text { ortografía. } \\
\text { - Útil para saber escribir. } \\
\text { - Comprender mejor el valenciano. } \\
\text { - Organizar la información. } \\
\text { - Me servirá para hacer un tutorial en } \\
\text { el trabajo. } \\
\text { - Me fijo más } \\
\text { - No solo el contenido del tutorial me ha } \\
\text { ayudado a mejorar mi expresión oral } \\
\text { y escrita. } \\
\text { - Las actividades servían para repasar. } \\
\text { - Un forma sencillas de explicar las } \\
\text { cosas, en el futuro te enseña a } \\
\text { expresarte ante otras personas y saber } \\
\text { ortografía para redacta. } \\
\text { - Método de trabajo que cuesta poco } \\
\text { tiempo y es satisfactorio } \\
\text { - Bien porque al escucharlo se entiende } \\
\text { mejor. } \\
\text { - Me costó prepararlo y ese tiempo } \\
\text { me sirvió para aprendérmelo y no } \\
\text { olvidarlo y si ocurre puedo volver a } \\
\text { ver mi tutorial. } \\
\text { - Comprender y expresarme mejor } \\
\text { oralmente. }\end{array}$ \\
\hline
\end{tabular}




\begin{tabular}{|l|l|l|}
\hline Exposiciones & - Muy chulo ver como otros alumnos & \\
& más pequeños atendían nuestras & \\
& explicaciones y aprendían,. & \\
- Ves como aprenden. & \\
- Entretenido y alegre los niños & respondían incluso mejor que nuestra & \\
& clase. \\
& - Divertido ver cómo aprendían con las & actividades que preparábamos. \\
& - Una buena experiencia. Los niños & \\
& aprendían & \\
\hline
\end{tabular}

Tabla 5. Descripción de las justificaciones sobre las observaciones literales y reflexiones de los alumnos de $3^{\circ}$ de ESO.

\subsubsection{Observaciones de los alumnos de Primaria}

Se diferenció entre el reconocimiento del contenido de las exposiciones, en las cuales recordaban qué actividades sobre ortografía habían realizado y qué normas les enseñaron. La mayoría recordaban el título del tutorial y alguno recordaba incluso alguna particularidad de la norma en valenciano.

Se preguntó qué hicieron bien los alumnos de $3^{\circ}$ de ESO y es significativo cómo los alumnos de Primaria hicieron mención a aspectos propios de la expresión oral: quedarse en blanco, no vocalizar, la entonación, la pronunciación, tener vergüenza.

\section{Conclusión}

El hecho de trabajar con los nuevos géneros discursivos que surgen en la era digital como el vídeo tutorial, resulta motivador y contribuye a conocer los procedimientos lingüísticos que entran en juego en los mismos. Partíamos con una mayoría de alumnos cuya lengua materna era el castellano y de los cuales un alto porcentaje consideraron que era una tarea con dificultad. Sin embargo, las apreciaciones han destacado por ser positivas y motivadoras.

Hemos podido observar que el vídeo tutorial facilita la construcción de un discurso oral y se visualiza la necesidad de una planificación. Con la elaboración del mismo, los alumnos pueden realizar numerosas grabaciones buscando la corrección de la producción oral de elementos prosódicos, la escucha individual y en grupo, por lo que estos ensayos fomentan la interacción y expresión oral.

En las exposiciones orales de las instrucciones entre iguales se facilita la evaluación por competencias, ya que evaluar por competencias requiere evaluar sistemas de comprensión acción. Por esto, mediante una evaluación entre iguales, fomentamos oportunidades de aprendizaje, incluso, ocasiones de autoconocimiento del aprendiz, ya que mediante el intercambio oral y registros de grabaciones de los alumnos, con el diálogo entre iguales o la propia planificación de la estructura del discurso oral que elaboran, estamos orientando con esta experiencia hacia la autorregulación. Todo esto entendemos que es importante para desarrollar la competencia oral. 
Es importante destacar que el docente en esta experiencia realiza una función tutorial, esto es, una muestra más de las nuevas competencias que debe desarrollar el docente. Entre ellas podríamos destacar: enseñar, planificar, crear contextos de aprendizaje y climas positivos de aprendizajes. Es aquí donde se demuestra el papel fundamental en el diseño de actividades y que se pueden utilizar herramientas TIC sin abandonar modelos de secuencias didácticas centradas en la planificación del discurso oral.

El escenario educativo que se presenta en la experiencia de esta propuesta didáctica no solo introduce las TIC omnipresentes en los alumnos de nuestras escuelas, sino que se aborda un escenario de vivencias y experiencias (Pérez Gómez, 2012).

En esta experiencia de aula, hay que destacar que predomina un contexto de producción. Tal y como describe Pérez Gómez (2012), en estos contextos se suelen desarrollar problemas reales que en nuestro caso serían las normas de ortografía; con fuentes primarias de información, como los propios tutoriales elaborados y un fomento de la cooperación. La evaluación es una herramienta privilegiada que colabora en el conocimiento del grado de desarrollo para ayudar a mejorar y autorregularse. El docente se preocupa por ayudar a aprender y facilitar los procesos de desarrollo de las cualidades básicas de sus alumnos. Por tanto, es importante destacar que el desarrollo de la competencia oral también puede encontrarse en el diseño de nuevos escenarios de aprendizaje y proyectos derivados de la era digital.

Esta experiencia supone el desarrollo de un contexto educativo en el cual los alumnos se encuentran en una situación concreta a la que tienen que responder y es también una de las responsabilidades prioritarias como docentes educadores.

Los docentes somos testimonios de competencias que proponemos desarrollar en los aprendices (Pérez Gómez, 2012). En el diseño estaría la clave para crear ese contexto de enseñanza aprendizaje sin olvidar que el uso de las TIC debe enmarcarse en un proyecto metodológico.

\section{Referencias bibliográficas}

Bakhtín, M. (1982). Estética de la creación verbal. Madrid. Siglo XXI

Beltrán, V. A. (2016). Los modelos de género discursivo en la planificación y revisión textual. Análisis del uso de modelos en alumnos de $3^{\circ}$ ESO (Tesis Doctoral). Universitat de València.

Camps, A., y Ribas, T. (2000) La evaluación del aprendizaje de la composición escrita en situación escolar. Madrid: MECD.

Cassany, D. (2002). La alfabetización digital. XIII Congreso Internacional de la Asociación Lingüística y Filológica de América Latina (ALFAL). San José, Universidad de Costa Rica.

Decreto 112/2007, de 20 de julio, del Consell, por el que se establece el currículum de la Educación Secundaria Obligatoria a la Comunidad Valenciana. [2007/9717]. (DOCV, 24-7-2007). Última fecha de consulta: 15 de junio de 2018 http://www.dogv.gva.es/datos/2007/07/24/ pdf/2007_9717.pdf.

Kolmos, A. (2004). Estrategias para desarrollar currículos basados en la formulación de problemas y organizados en base a proyectos. Educar, 33, 77-96. 
Martínez, J. R. (2002). La expresión oral. Contextos educativos: Revista de Educación, 5, 57-72.

Martín, J. G., y Martínez, J. E. P. (2018). Aprendizaje basado en proyectos: método para el diseño de actividades. Revista Tecnología, Ciencia y Educación, (10), 37-63.

Mostacero, R. (2004). Oralidad, escritura y escrituralidad. Sapiens. Revista Universitaria de Investigación, 5(1), 53-75.

Navarro Gutiérrez, J. F. (2013). Audioteca de recursos de tipología textual: Una propuesta didáctica para el desarrollo de la competencia oral. Universidad Pública de Navarra.

Núñez, Ma P. (2003). Valor educativo de la oralidad en la enseñanza escolar de la lengua y literatura. Revista de Educación de la Universidad de Granada, 16, 359-377.

Pérez Gómez, A. I. (2012). Educarse en la era digital: La escuela educativa. Madrid: Morata.

Real Decreto 1105/2014, de 26 de diciembre, por el que se establece el currículo básico de la Educación Secundaria Obligatoria y del Bachillerato. Recuperado de https://www.boe.es/boe/ dias/2015/01/03/pdfs/BOE-A-2015-37.pdf

Ribera, P. (2008). El repte d’ensenyar a escriure. L'inici de la producció de textos en Educación Infantil. València: Perifèric.

Sales Arasa, C. (2009). El método didáctico a través de las TIC: Un estudio de casos en las aulas. Valencia: Nau Llibres.

Vilà, M., y Gómez, C. B. (2005). El discurso oral formal: contenidos de aprendizaje y secuencias didácticas. Barcelona: Graó.

Vilà, M. (2011). La competència oral a l'educació obligatòria. Articles: Revista de Didàctica de la Llengua i de la Literatura, (55), 69-83. 